\title{
AIN CERAMICS METALLIZATION WITH TITANIUM BY MEANS D-GUN SPRAYING METHOD
}

\author{
Beata SKOWROŃSKA, Tomasz CHMIELEWSKI, Tadeusz SAŁACIŃSKI, Rafal SWIERCZ \\ Warsaw University of Technology, Warsaw, Poland, EU, \\ b.skowronska@wip.pw.edu.pl
}

https://doi.org/10.37904/metal.2019.892

\begin{abstract}
The article presents an innovative method of metallization of ceramics based on detonation spraying process. New approach consists on exposition of influence mechanical deliver of energy for joining process. In the DGun spraying process the energy necessary for deposition the metallic coating onto ceramic substrate is delivered mainly in mechanical way. In the described case, the titanium particles, shot from the spraying gun barrel, impinge onto AIN ceramic surface, and their kinetic energy is transformed into heat delivered directly to the zone coating/substrate joint being formed. The powder being sprayed is also heated to a high temperature, however, the high kinetic energy of the particles in the spraying stream is dominant for the distinguishing properties of the coating.
\end{abstract}

Keywords: Detonation spraying, coatings, ceramics, metallization

\section{METALLIZATION OF CERAMICS}

Thermal spraying is one of the most effective method to protect the material from wear, high temperature corrosion, stresses and erosion and increasing the life of materials in use [1-7]. Detonation gun spraying is one of the thermal spraying techniques known for providing hard, wear resistance and dense structured coating with compressive residual stresses [8-12]. The proper application of the thermal spraying method can provide many savings when used in electro-technical, electronic, and electron industry. The metallization of ceramic materials is often necessary in the advanced technology. But joining of ceramic to metals reveals several problems resulting from the significant differences in material properties. The ceramic-to-metal joints are used nowadays in many areas for example: optoelectronics, fuel cells, laser techniques, semiconductors, microwave lamps, ultrahigh vacuum techniques [13-17]. The metallic coatings deposited by means thermal spraying on the ceramic substrate can also be used as an interface layer applied for brazing or friction welding with metals [13]. The difficulties in joining ceramics with metals are associated with the differing properties of two materials, such as: lack of wettability of ceramics by liquid metals, the lack of chemical interactions between these two materials, weak diffusion of metals into ceramics, drastic difference in the thermal expansion coefficients $\alpha$ and in thermal conductivity $\lambda$ (properties especially important from the point of view of the residual stress state induced in the joint) [18-21]. The diffusion-based processes suitable for joining ceramics with metals must be conducted at high temperature in vacuum, require additional expensive chemical and active substances to be used, and the process duration is long. The mechanism of creation of a joint at the interface of two solid bodies can be considered in thermodynamic approach which assumes that bonding is the transition of a system composed of two components, which sum of free surface energies (before joining) is higher than interfacial free energy (after joining). Assuming that every physical system tends to achieve the minimum free energy. The thermodynamic approach [22] (proposed by Professor Jacek SENKARA) to the bonding process can be illustrated by the curve in Figure 1. Point 1 represents the metastable state with the free enthalpy $\mathrm{G}_{1}$ of two free surfaces. In point 2 the joint has already formed, and the free enthalpy $G_{2}$ is now lower. The force which drives the transition from state 1 to state 2 is equal to the difference between the level of two free energies $\Delta G$. The transition from state 1 to state 2 requires overcoming the energy barrier $Q$ i.e. the activation energy must be brought and used for removing imperfections of the free surfaces. In situation when the temperature is lower, a pressure must be additionally applied, which facilitates a plastic behavior of the material and speeds up the diffusion. These phenomena are utilized in the detonation spraying method described in the present 
article, in which the required activation energy ( $Q$ in Figure 1$)$ is delivered to the joining process in a mechanic way, by means the transformation of kinetic energy into heat energy which is dissipated directly within the zone of the joint being formed.

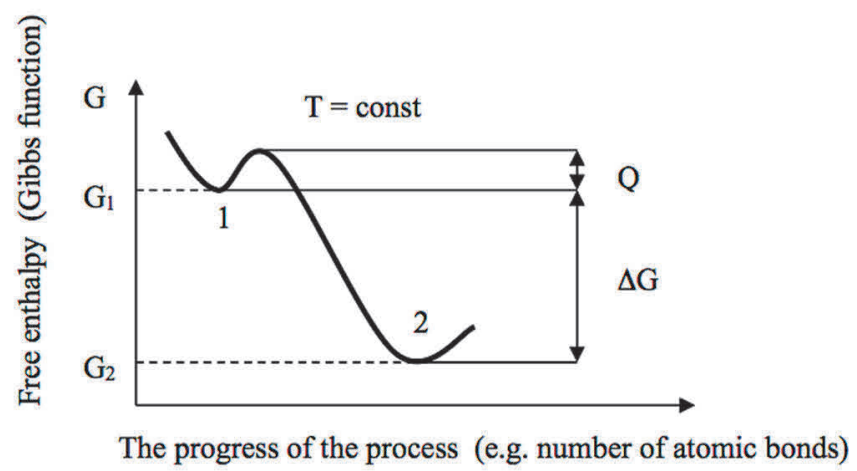

Figure 1 Variation of the free energy of the system being joined: 1) state before joining,

2) state after the bonding

The aim of the study was to describe and highlight the specific properties and condition of detonation spraying process could favor and amplify joining of metal coating with ceramic substrate in the context of facilitating diffusion phenomena and atomic bond formation at the interface.

\section{SUBSTRATE AND COATING MATERIALS}

The materials to be joined were AIN ceramic as the substrate and titanium (Grade 2) as the coating material. AIN was selected by way of literature [13] analysis as a widely used material, has the uppermost significance in technical applications. On the other hand, the choice of titanium as the coating material was based on literature reports $[15,16,18]$ which describe titanium as the material that actively enhance the wetting of ceramics by metals. In view of the potential strong chemical affinity of titanium to nitrogen and aluminum new compounds of the Ti-Al and Ti-N systems are formed.

\section{DETONATION SPRAYING PROCESS}

Thermal spraying, in its various versions [1,8-10], is widely used for modifying or regenerating the surface of many products. Detonation sprayed coatings can play important role in protecting materials and alloys from wear and corrosion phenomena. Detonation spraying is based on controlled detonation of a mixture of gases, such as energetic (most often acetylene and propane) and oxygen, triggered by an electric discharge between the electrodes of sparking plug. The detonation of the energetic gas generates a shock wave, which heats up the individual particles of the coating material and accelerates them in the barrel of a special gun to velocities in range of about $600 \div 1200 \mathrm{~m} / \mathrm{s}$. Coatings sprayed by the D-gun method have usually high parameters of properties, and comparatively high adhere to the substrate. In the detonation spraying process, the coating is deposited in a discrete (discontinuous), during each detonation cycle hot coating material particles impinge on the substrate, they are fixed to its surface on a certain area about $20 \mathrm{~mm}$ in diameter forming a layer about 10 $\mu \mathrm{m}$ thick. The frequency of the detonations can be controlled and mainly ranges from 1 to $10 \mathrm{~Hz}$, thanks to which the heat generated in the previous cycle can be dissipated within the substrate before the subsequent layer is deposited. The Table 1 shows the parameters of the spray process used in this experiment.

The temperature at which the metal-ceramic joints forms is here the lowest among all the HVOF methods, which is advantageous from the point of view of the residual stress induced in the coating/substrate system. D-gun process proceeds in the pulsed way. The heat delivered to the joint being formed is mainly due to the transformation of the kinetic energy of the spraying powder particles which impinge in the ceramic substrate. The participation of diffusion in the formation of the ceramic-metal joints could be substantial since it is 
enhances by the high dislocation density, the impact character of the load imposed, by the detonation wave, and the high rate of sever plastic deformation of the material of the growing coating within the coating-substrate region.

Table 1 Arc spraying parameters

\begin{tabular}{|c|c|}
\hline Parameter & Value (unit) \\
\hline Frequency of detonation & $4(\mathrm{~Hz})$ \\
\hline Propane pressure & $0.08(\mathrm{MPa})$ \\
\hline Oxygen pressure & $0.12(\mathrm{MPa})$ \\
\hline Nitrogen pressure & $0.6(\mathrm{MPa})$ \\
\hline Ti powder particle size & $325 \mathrm{MESH}$ \\
\hline Distance between the barrel end and the substrate & $160(\mathrm{~mm})$ \\
\hline
\end{tabular}

\section{MODELLING THE PHYSICAL PHENOMENA THAT OCCUR DURING THE IMPACT OF TI PARTICLE ONTO ALN SUBSTRATE SURFACE}

The models used in the present experiments simulated the changes of the geometrical shape of the Ti particle when it was plastic deformed during its impact onto the substrate, and the instantaneous distributions of the stress and temperature inducted in the border particle-substrate during and as the effect of impact. Because from the point of view of the formation of the joint the ceramic-metal boundary is important, the analysis was limited with what happened when a single metal particle impinged on the ceramic substrate at a certain velocity. The numerical simulation was performed in dynamic systems using the ANSYS Autodyne v. 13 software. The temperature and stress state prevailing in the region of the joint formation, and the degree of deformation of the metallic particle were modeled. Figure 2a presents the adopted model of the particle/substrate system. The average particle diameter $44 \mu \mathrm{m}$ was assumed to be equal to the average size of the particle used (MESH 325). The thickness of the AIN substrate was $200 \mu \mathrm{m}$. The temperature of the particle moving in exhaust gases after the detonation was adopted in medium level, $2773 \mathrm{~K}$ and its average velocity to be $700 \mathrm{~m} / \mathrm{s}$. The finite element mesh (element size $-0.5 \mu \mathrm{m}$ ) was constructed in the Euler domain. Its fragment is shown in Figure $\mathbf{2 b}$. Figure 3 shows the results concerning the Ti particle deformation. We can see that, in the successive time moments after the Ti particle impinges onto the ceramic substrate and takes part in the formation of the joint (Ti particle/AIN substrate) it is being heavily deformed (becomes flattened), and its edges can be separated from the substrate (Figure 3a). The final height of the deformed particle is about $15 \mu \mathrm{m}$ and its diameter is about $116 \mu \mathrm{m}$.

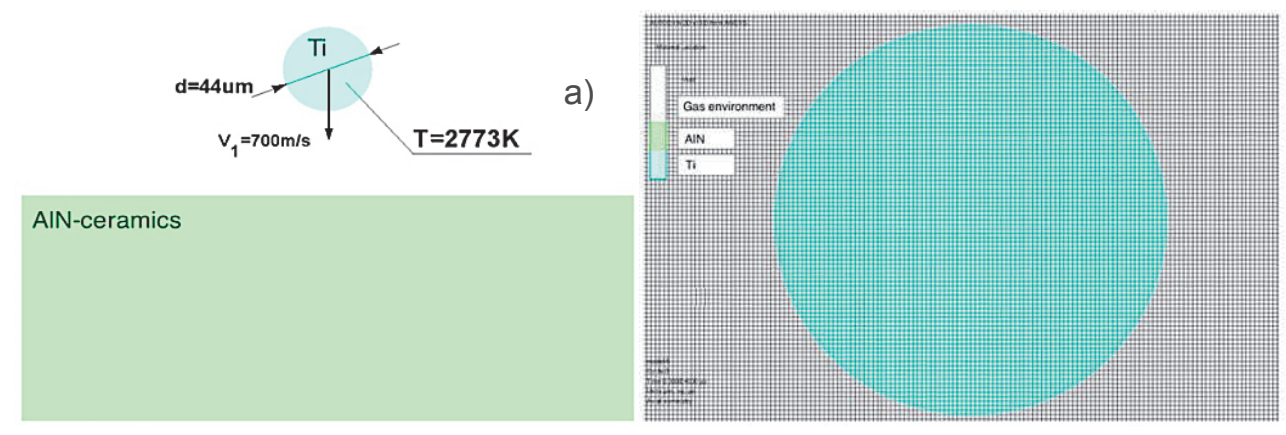

b)

Figure 2 Schematic representation of the particle/substrate model: a) Ti particle detonation sprayed on an AIN substrate; b) Fragment of the finite element mesh

Figure $3 \mathbf{b}$ shows the distribution of the temperature on a transverse cross-section of the deformed $\mathrm{Ti}$ particle at $50 \mathrm{~ns}$ after beginning of contact in collision. The red-colored area represents the small zone with the highest temperature, about $3500 \mathrm{~K}$. 


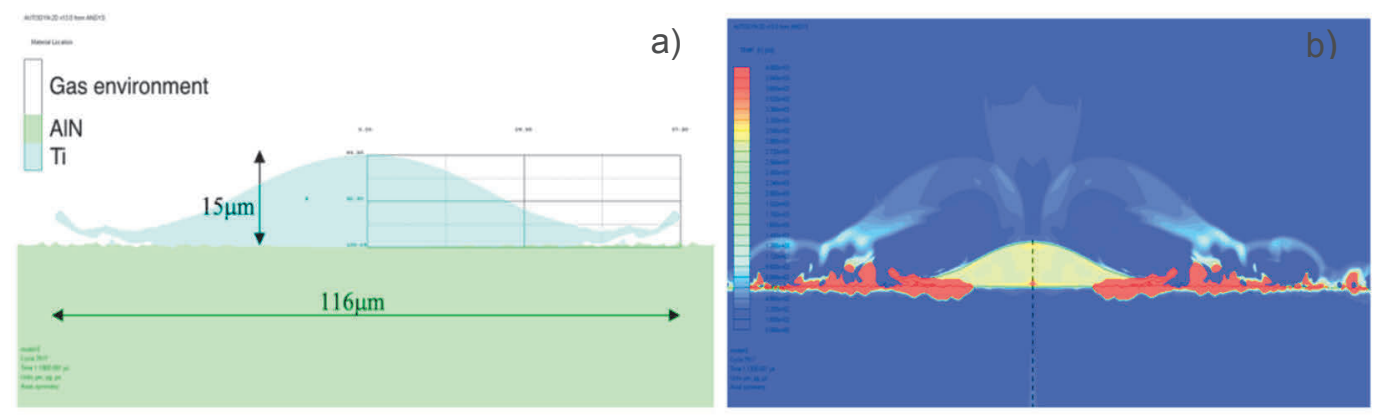

Figure 3 a) Deformed Ti particle deposited on the AIN substrate, b) temperature distribution in cross-section of deposited particle at time of 50 ns after the particle impact

Figure 4 shows the temperature distributions along the axis of the particle/substrate system recorded at the time when the temperature value was the highest i.e. $50 \mathrm{~ns}$ after beginning of the impact. The temperature and its gradient are the highest at the Ti/AIN interface and, then, it quickly decreases along the depth of the ceramic substrate.

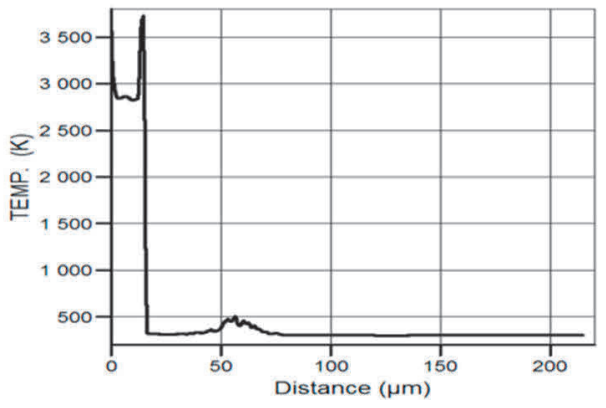

Figure 4 Temperature distribution along the axis of symmetry of the particle/substrate system measured at $\mathrm{s}$ time of $50 \mathrm{~ns}$ after the particle impact

Figure 5 and Figure 6 show the distribution of the reduced stress inducted in the substrate according to the Huber hypothesis. The variations of the stress magnitude and distribution with time were analyzed for $50 \mathrm{~ns}$ from the moment of the particle impact. Figure $\mathbf{5}$ shows the time variation of the stress induced in the substrate as a result of the impact of the Ti particle. It can be seen that the stresses propagate from the point of the $\mathrm{Ti}$ impact mainly into the depth of the ceramic but also throughout the expanding contact plane. Figure $\mathbf{5}$ shows the distribution of reduced stress in the ceramic from side of the Ti-AIN interface to the opposite surface, according to the Huber-von Mises hypothesis, in the axis of symmetry of the particle/substrate system measured at time of $50 \mathrm{~ns}$ after the particle impingement.

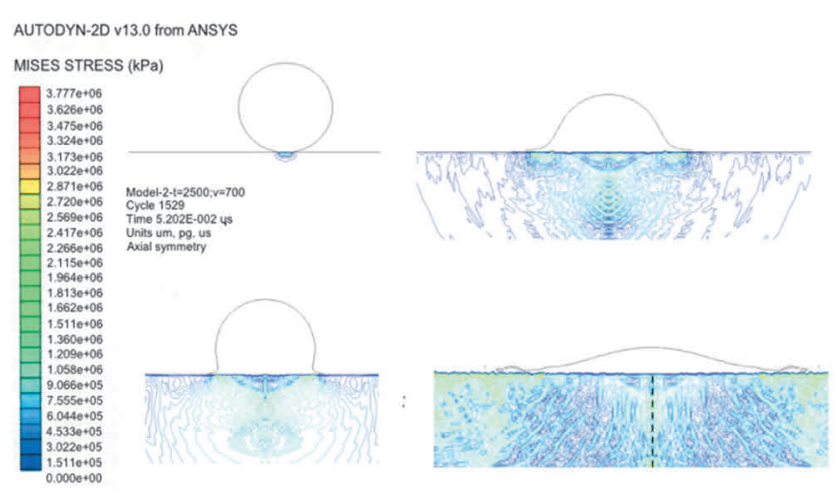

Figure 5 Distribution of the reduced stress generated in the ceramic substrate mapped during $50 \mathrm{~ns}$ after the particle impingement 
The high amplitude of the stress variation versus the distance down through the thickness is probably associated with the short time, which elapses from the particle impingement and with the elastic response of the ceramic substrate. The deep oscillations of the stress magnitude visible in the ceramic to a depth of about $150 \mu \mathrm{m}$ (Figure 6) can be attributed to the elastic vibrations induced by the particle impingement.

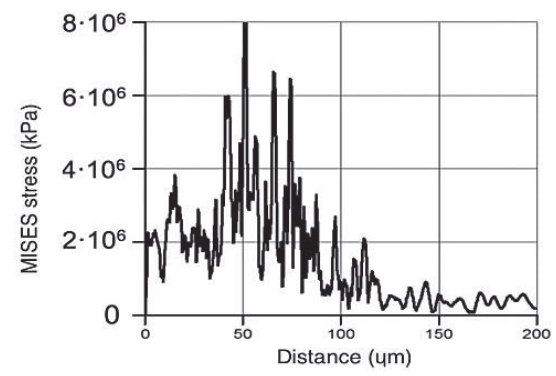

Figure 6 Distribution of the reduced stress generated in the ceramic substrate mapped during $50 \mathrm{~ns}$ after the particle impingement

Modeling of the physical phenomena, which occur in dynamic systems is significant difficult and the results must always be referred to the time instance during the process at which they have been obtained. Presented results indicate that characteristic parameters of the detonation spraying process, i.e. temperature, temperature gradient and pressure, are the highest at about 50 ns after the impingement of the Ti particle on the AIN ceramic substrate. These results are significant from the point of view of joining a metallic coating with the ceramic substrate, both in the solid state, using the detonation spraying technique.

\section{MICROSTRUCTURE OF THE TI COATING AND INTERFACE WITH THE SUBSTRATE}

In the first phase, the analysis was done via optical microscope produced by the Olympus company. An observation was conducted of metallographic sample of the Ti sprayed coating, under x100 mag. It is seen that the structure of deposited layer is uniform and consists of multilayered squeezed and tightly packed particles of coating material. The coating shows continues contact with the substrate and good adhesion. The microstructure (Figure 7) of titanium coating sprayed onto the AIN substrate was analyzed as well via scanning electron microscope JEOL (USA). The coating shows continuous connection to the substrate filling each visible surface micro roughness. The linear element distribution profiles indicate that there was not a deep mutual penetration of AIN and $\mathrm{Ti}$. There are however no signs of the visible presence of a transition diffusion layer which would form during the D-gun spraying process. However, result of adhesion test according to EN ISO 14916 shows than tensile strength of the sprayed coating reached a mean value of $23.33 \mathrm{MPa}$ (standard deviation $1.81 \mathrm{MPa}$ )
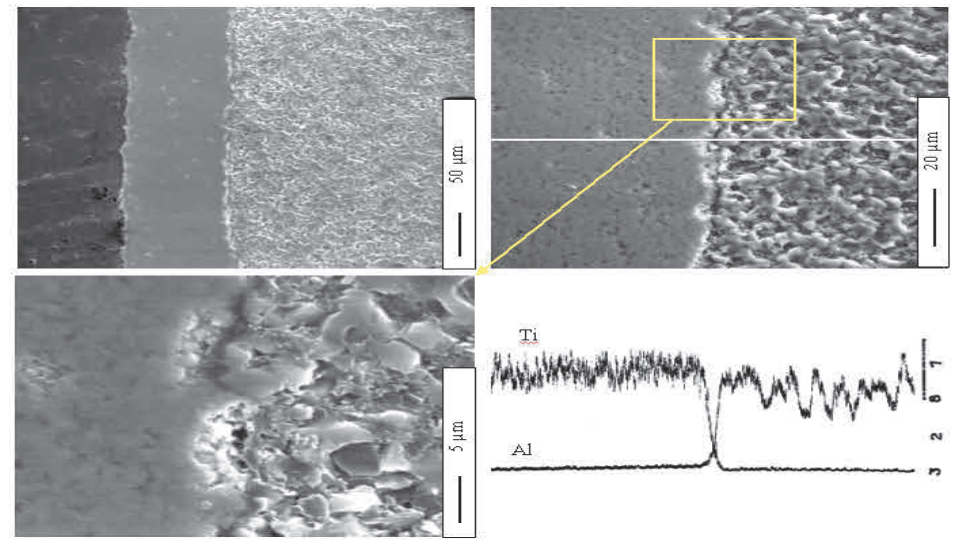

Figure 7 The microstructure of titanium coating deposited onto the AIN substrate by means the D-gun technique with linear distribution of $\mathrm{Ti}$ and $\mathrm{Al}$ elements 


\section{CONCLUSIONS}

Investigations and simulations have shown that the energy delivered to the metallic coating - ceramic substrate system in a mechanical way plays a very effective role in joint formation during metallization of ceramic materials. The specific advantage of this method lies in that it permits delivering a specified portion of energy to a precisely defined place where the coating/substrate interface is to be formed. In the light of presented results and in agreement with the respective theory concerning the effects of the temperature, pressure, deformation degree, and time on the formation of a joint, it could be concluded that the conditions that prevail during the proposed detonation-spraying process are favorable for the formation of a strong and durable joint between the Ti coating and the AIN ceramic substrate. The transformation of the Ti particle kinetic energy into heat energy results in a high temperature being locally generated at the interface between the Ti particle and the AIN ceramic substrate. Described conditions favor the formation of high-quality adhesive joint, even though, because of the very short duration of thess phenomena, the formation of a narrow diffusion-type transition zone in the joint is little probable. The significant advantage of the proposed solution over the traditional methods is that the only region heated during the process is the surface of the modified substrate. Taking into account the results obtained in described experiments and the advantages of the proposed, inexpensive method we believe that it can be successfully used in a variety of industrial applications as an alternative method of metallization of AIN ceramics with titanium.

\section{REFERENCES}

[1] SENDEROWSKI, C.J. Nanocomposite Fe-Al Intermetallic Coating Obtained by Gas Detonation Spraying of Milled Self-Decomposing Powder. Journal Therm. Spray Technol. 2013. vol. 23, pp.1124-1134.

[2] CZUPRYŃSKI. A., GORKA. J., ADAMIAK, M. Examining properties of arc sprayed nanostructured coatings. Metalurgija. 2016. vol. 55, no. 2, pp. 173-176.

[3] GÓRKA, J., CZUPRYŃSKI, A. The properties and structure of arc sprayed coatings alloy of Fe-Cr-Ti-Si-Mn. International Journal of Modern Manufacturing Technologies. 2016. vol. 8, no. 1, pp. 35-40.

[4] WYPYCH, A. Laser creation of padding welds hard, abrasion- and corrosion resistant, Welding Technology Review. 2017. vol. 89, no. 10, pp. 61-66.

[5] $\quad$ $\quad$ ATKA, L., CHICOT, D., CATTINI, A., PAWŁOWSKI, L., AMBROZIAK, A. Modeling of elastic modulus and hardness determination by indentation of porous yttria stabilized zirconia coatings. Surface and Coatings Technology. 2013. vol. 220, pp. 131-139.

[6] ŻÓRAWSKI, W., MAKRENEK, M., SOBOŃ D. Properties and application of coatings sprayed with cold gas. Welding Technology Review. 2018. vol. 90, no. 10, pp.44-47.

[7] CHMIELEWSKI, T., SIWEK, P., CHMIELEWSKI, M., PIĄTKOWSKA, A., GRABIAS, A., GOLAŃSKI, D. Structure and Selected Properties of Arc Sprayed Coatings Containing In-Situ Fabricated Fe-Al Intermetallic Phases. Metals. 2018. vol. 8, no. 12, 1059.

[8] RAJASEKARAN, B., SUNDARA, R.G.S., JOSHI, S.V., SUNDARARAJAN, G. Influence of detonation gun sprayed alumina coating on AA 6063 samples under cyclic loading with and without fretting. Tribol. Intern. 2008. vol. 41, pp. 315-322.

[9] PANIN, S., VLASOV, I., DUDINA, D., ULIANITSKY, V., STANKEVICH, R., BATRAEV, I., BERTO, F. Mechanical Characterization of Composite Coatings Formed by Reactive Detonation Spraying of Titanium. Metals, 2017. vol. 7, 355.

[10] SENDEROWSKI, C., BOJAR, Z., WOLCZYNSKI, W., PAWLOWSKI, A. Microstructure characterization of D-gun sprayed Fe-Al intermetallic coatings. Intermetallics, 2010. vol. 18, no. 7, pp. 1405-1409.

[11] LAKHWINDER, S., VIKAS, C., GREWAL, J.S. A review on detonation gun sprayed coatings. Journal of Minerals \& Materials Characterization \& Engineering. 2012. vol. 11, no. 3, pp. 243-265.

[12] CHMIELEWSKI, T., GOLAŃSKI, D., HUDYCZ, M., SAŁACIŃSKI, T., ŚWIERCZ, R., Surface and structural properties of titanium coating deposited onto AIN ceramics substrate by friction surfacing process. Przemyst Chemiczny. 2019. vol. 98, no. 2), pp. 1000-1005. 
[13] SOSINOWSKI, Ł., ROZENEK, M. High-performance electrical discharge machining of small hole in metallic ceramic composites. Welding Technology Review. 2018. vol. 90, no. 3, pp. 21-25.

[14] OLESIŃSKA, W., KALIŃSKI, D., CHMIELEWSKI, M., DIDUSZKO, R., WŁOSIŃSKI, W.K. Influence of titanium on the formation of a „barrier” layer during joining an AIN ceramic with copper by CDB technique. Journal of Materials Science: Materials in Electronics. 2016. vol. 17, no. 10, pp. 781-788.

[15] CHMIELEWSKI, M., PIETRZAK, K. Metal-ceramic functionally graded materials - Manufacturing, characterization, application. Bull. of the Polish Academy of Science. 2016. vol. 64, no. 1, pp. 151-160.

[16] SALACINSKI, T., WINIARSKI, M., CHMIELEWSKI, T., SWIERCZ, R. Surface finishing using ceramic fibre brush tools. In METAL 2017: 26th International Conference on Metallurgy and Materials. Ostrava: TANGER, 2017, pp. 1220-1226.

[17] IWASZKO, J., KUDŁA, K., FILA, K. Friction stir processing of the AZ91 magnesium alloy with SiC particles. Archives of Materials Science and Engineering. 2016, vol. 77, no. 2, pp. 85-92.

[18] SKOWROŃSKA, B., SZULC, J., CHMIELEWSKI T., SAŁACIŃSKI T., SWIERCZ, R., Properties and microstructure of hybrid PLASMA+MAG welded joints of thermomechanically treated S700MC steel. In METAL 2018: 27th International Conference on Metallurgy and Materials. Ostrava: TANGER, 2018, pp. 849-854.

[19] PRESZ, W., CACKO, R. Bimetallic micro-punches for micro-blanking processes, Arch. Metall. Mater. 2018. vol. 63, no. 1, pp. 29-34.

[20] FYDRYCH, D., ŚWIERCZYŃSKA, A., ROGALSKI, G., Effect of underwater wet welding conditions on the diffusible hydrogen content in deposited metal. Metallurgia Italiana. 2015, vol. 107, no. 11-12, pp. 47-52.

[21] SLACK, G., TANZILLI, R.A., POHL, R.O., VANDERSANDE, J. W. The intrinsic thermal conductivity of AIN. J. Phys. Chem. Solids. 1987, vol. 48, no. 7, pp. 641-647.

[22] SENKARA, J., Control of the interfacial boundary structure of dissimilar welded joints. Welding Technology Review. 2002. vol. 74, no. 8-10, pp. 87-89. 